\title{
Detecting decreased sexual health with MDHAQ-S
}

\author{
Kristina Areskoug-Josefsson ${ }^{1,2^{\star}}$, Charlotte Ekdahl $^{1}$, Ulf Jakobsson ${ }^{3}$, Gunvor Gard ${ }^{1}$ \\ ${ }^{1}$ Department of Health Sciences, Division of Physiotherapy, Lund University, Lund, Sweden; \\ *Corresponding Author: kristina.areskoug@telia.com \\ ${ }^{2}$ Värnamo Hospital, Samrehab, Värnamo Sjukhus, Värnamo, Sweden \\ ${ }^{3}$ Center for Primary Health Care Research, CRC, Lund University, Lund, Sweden
}

Received 12 April 2013; revised 12 May 2013; accepted 6 June 2013

Copyright (C) 2013 Kristina Areskoug-Josefsson et al. This is an open access article distributed under the Creative Commons Attribution License, which permits unrestricted use, distribution, and reproduction in any medium, provided the original work is properly cited.

\begin{abstract}
There are instruments that measure sexual function or sexual health for persons with RA, but since sexual health is a sensitive issue, the hypothesis is that it would be easier to have a standard questionnaire that could indicate the need for communication about sexual health issues instead of an extra questionnaire with more detailed questions on sexual health. The aim of the study is to find out whether sexual health difficulties can be screened by factors included in the MDHAQ-S for persons with RA. This study explores the relation between factors included in the MDHAQ-S and the Sexual Health Questionnaire (QSH) using a mixed methods design combining quantitative and qualitative data. The MDHAQ-S covers sexual health issues, not only by using the question on sexual health, but also on other factors included in the questionnaire such as increased pain, fatigue, depression, anxiety, physical capacity, level of physiccal activity and body weight. To explore decreased sexual arousal, decreased sexual satisfaction and decreased sexual well-being, in-depth interviews must be held with persons with RA, either using a sexual health questionnaire or in a clinical interview.
\end{abstract}

Keywords: Sexual Health; Rheumatoid Arthritis; Mixed Methods; Rehabilitation; Health Assessement

\section{INTRODUCTION}

Sexual health is connected to self-esteem, intimate relationships and general quality of life and is defined by the World Health Organization as a state of physical, mental and social well-being in relation to sexuality [1].
Good sexual health is an important factor in achieving a desired quality of life, even if the essence of good sexual health actually consists of differs between individuals. A description of what good sexual health is can also vary individually across the lifespan due to life circumstances. However, sexual life satisfaction is one of the two main predictors of global life satisfaction for persons with rheumatoid arthritis (RA) [2]. Being able to perform sexual activities is included in important life activities for persons with RA [3], and sexual health is often affected negatively by the disease [4-6]. A decrease in sexual health can be due to fatigue, pain, decreased physical capacity, negative body image and/or depression. Factors that might be of importance in detecting risk for decreased sexual health, for example pain, have been shown to have a significant correlation with sexual dysfunction in both men and women [7].

Communication about sexual health is an issue that should involve several health professions since multidisciplinary interventions are needed to improve sexual health [8]. Some health professionals hesitate to bring up the subject of sexual health with their patients, however, and sexual health issues are often not identified in patients with chronic diseases [9-11]. Since communication concerning sexual health is scarce among health professionals and patients with RA, it is important to find interview guide recommendations in clinical practice that are within the comfort zone for both patients and health professionals. Earlier research [12] shows that patients prefer health professionals to bring up the subject of sexual health with them. A recent study showed that patients with RA would not have brought up sexuality issues at all unless these issues were part of a questionnaire at a clinical visit [7]. Communicating about sensitive issues such as sexual health can be facilitated by the use of a questionnaire, in order to find indications of a need for information or support to the patient [13].

It would be of value to use standardized questions that 
could detect a patient's perceived level of sexual health. Patient questionnaires are the most significant predictors of severe long-term outcomes in patients with RA [14]. There are instruments that measure sexual function or sexual health in persons with RA, but since sexual health is a sensitive issue, the hypothesis is that it would be easier if a standard questionnaire could indicate the need for communication about sexual health issues instead of using an extra questionnaire with more detailed sexual health questions. One of the most frequently used questionnaires for patients with RA is the Stanford Health Assessment Questionnaire (HAQ) [15,16], which does not include questions concerning sexual health [17]. The revised version, the Multi Dimensional Health Assessment Questionnaire (MDHAQ), has one question covering different symptoms of RA that includes a choice concerning an effect on sexual function [18]. The MDHAQ is regularly used both in research and in clinical care internationally and is available in a Swedish version, the MDHAQ-S [19]. The MDHAQ consists of the following parts: physical function, psychological status, pain, global health, fatigue, morning stiffness and exercise habits, and includes Routine Assessment of Patient Index Data 3 (RAPID3) and Rheumatoid Arthritis Disease Activity Index (RADAI) self report joint count [20] as well as a symptom list and recent medical history [18]. The items included in the MDHAQ can be related to sexual health. There are questionnaires concerning sexual health for persons with RA, and here we have used the Questionnaire of Sexual Health (QSH) together with the MDHAQ$\mathrm{S}[21]$.

\section{AIM}

To find out whether sexual health difficulties can be screened by factors included in the MDHAQ-S for persons with RA.

\section{Research Goals}

- To study the correlation between the factors included in the MDHAQ-S and the QSH.

- To identify predictors of sexual well-being in persons with RA.

- To describe the participants' reasoning concerning factors affecting their sexual health.

\section{MATERIAL AND METHOD}

The hypothesis is that standardized questions, such as those included in the MDHAQ-S, correlate with decreased sexual health. This study explores the relation between factors included in the MDHAQ-S and the Sexual Health Questionnaire (QSH) [21]. A mixed methods design combining quantitative and qualitative data was chosen to complement, deepen the understanding of and support the findings of how different factors might affect sexual health $[22,23]$. The use of mixed methods research demands rigor to the quantitative and qualitative methods included [24]. The data were collected using two questionnaires, the MDHAQ-S and the QSH.

The QSH contains 21 questions: age, gender, civil status, partner's health status, body image, change in body image after onset of RA, effect of RA on sexual function, sexual well-being, sexual arousal, change in sexual arousal after onset of RA, sexual satisfaction, change in sexual satisfaction after onset of RA, status of relationship, effect of RA on relationship, importance of sexuality, connections between pain, fatigue, stiffness, physical capacity, positive feelings and experiences and sexual health, and how the respondent would like to be informed about sexual health for persons with RA. The questions in the QSH are written as claims with optional answers on Likert scales (3 - 5 options), except for the demographic questions and the question on information about sexual health, which had the following options: "I bring it up when there is need for it", "Health professionals bring up the subject", "Possibilities to contact by e-mail", "Written information in the waiting room", "Information on the internet", "I don't want sexual health to be brought up at all". The QSH includes the option of open answers to questions.

The internal consistency of the QSH, measured with Cronbach's alpha, was 0.74 [21]. The factor structure of the QSH, evaluated with principal component analysis (varimax rotation, Eigen value $>1$ ), shows three meaningful factors: sexual well-being, body image and relationship [21]. The factor "sexual well-being" contains five items; the factor "body image" contains two items and the factor "relationship" contains two items. The QSH has also shown good face validity [21].

The questions concerning earlier experiences of physiotherapy and communication of sexual health with health care professionals have been removed in the revised version of the QSH in order to gain a more focused view of sexual health issues.

The MDHAQ [18,20] starts with "physical function" including ten activities of daily living scored $0-3(0=$ "without any difficulty", 1 = "with some difficulty", 2 = "with much difficulty" and 3 = "unable to do"). The sum of the answers is divided by three, giving a score between 0 and 10. The second section, with three questions concerning psychological status, has scores of $0=$ "without any difficulty", 1.1 = "with some difficulty", $2.2=$ "with much difficulty", and 3.3 = "unable to do". The sums are added to a total sum of 0 - 9.9. The MDHAQ-S includes visual analogue scales with 21 circles measuring pain, global health and fatigue with a total score of $0-10$ in 0.5 units. The RADAI includes eight joints or joint groups scored $0,1,2$ or 3 . The RAPID3 scores (0 - 30 
scale) include four categories: High severity $>12$, Moderate severity $=6.1-12$, Low severity $=3.1-6$ and Remission $\leq 3$. The review of symptoms is a checklist of symptoms where boxes that have been checked are counted. Morning stiffness is rated by yes or no and the amount of time in minutes. Change in status is scored: 1 $=$ Much better, $2=$ Better, $3=$ Same, $4=$ Worse, $5=$ Much worse. Exercise frequency is scored $3=3$ or more times a week, $2=1-2$ times a week, $1=1-2$ times a month, $0=$ Do not exercise regularly, $9=$ Cannot exercise due to disability/handicap. The MDHAQ-S also includes questions about recent medical history, which are not scored.

The reliability of the MDHAQ-S has been tested with Cronbach's alpha, intra-class correlation and kappa statistics and has shown good reliability [19]. The content validity of the MDHAQ-S was tested with a content validity index, giving a range of $0.75-1.00$, with an average sum of 0.94 [19].

\subsection{Study Group}

\subsubsection{Quantitative Study Group}

Swedish speaking persons with diagnosed RA above 18 years of age from a rehabilitation clinic in Sweden were invited to participate. The aim was to include 80 persons with RA in the study. It was a consecutive sample with a response rate of $67.5 \%$, in total 54 participants. The participants' demographic data are shown in Table 1.

\subsubsection{Qualitative Study Group}

Participants from an earlier study [21] that had the same inclusion criteria as for the quantitative study group were included, together with the quantitative study group, in the analysis of the open answers to the QSH (Table 2).

\subsection{Data Collection}

The questionnaires were given to patients who agreed to participate in the study, either at the clinic or sent home to the participant. The patients answered both questionnaires at the same time.

\subsection{Data Analysis}

\subsubsection{Quantitative Analysis}

The collected data from the QSH and the MDHAQ-S were analyzed using descriptive statistics, frequencies and proportions, and were analyzed for correlation with Spearman's rank correlation for the items included as well as for the physical and psychological dimensions of the MDHAQ-S. Multiple regression analysis was performed to identify associated factors to sexual well-being.
Table 1. Demographic data of the quantitative study group.

\begin{tabular}{ccc}
\hline & Age average (range) & Living with a partner \\
\hline Women, $n=47$ & 57 years $(28-77)$ & 33 \\
Men, $n=7$ & 64 years $(51-72)$ & 5 \\
\hline
\end{tabular}

Table 2. Demographic data of the qualitative study group.

\begin{tabular}{ccc}
\hline & Age average (range) & Living with a partner \\
\hline Women, $n=98$ & 56 years $(19-77)$ & 73 \\
Men, $n=19$ & 62 years $(38-76)$ & 16 \\
\hline
\end{tabular}

The criterion variable was sexual well-being from the QSH, and the independent variables included from the MDHAQ-S were total score of physical function, total score of psychological function, pain, fatigue and general well-being. Descriptive statistics and independent sample test were used to describe the subgroup expressing decreased sexual health on the MDHAQ-S review of symptoms, as well as the subgroups with high levels of regular exercise and high Body Mass Index (BMI). The subgroup of those describing decreased sexual health was chosen since it is a direct question about sexual health, the exercise subgroup was chosen due to the known positive effects of a physically active lifestyle on sexual health and the subgroup of overweight (BMI $\geq 25)$ was chosen on the basis of the results from the open answers in the questionnaire.

\subsubsection{Qualitative Analysis}

In the QSH, participants had the opportunity to describe their experiences in their own words as to whether and how RA had affected their sexual health. The open answers of the QSH were analyzed with content analysis [25]. Content analysis has been used in other studies that have analyzed open answers in questionnaires in combination with quantitative data analysis [26-28].

Each question was analyzed separately, and the content analysis consisted of the following procedure [25]:

- Reading and re-reading all answers to get a sense of the material.

- Sorting the material into meaning units.

- Coding meaning units.

- Comparing codes concerning similarities and differences.

- Differences between the two researchers concerning coding and categorisation were discussed from the view of the question and the completion of the answer.

- Categorizing codes and comparing similarities and differences.

- Differences between the two researchers concerning coding and categorisation were discussed from the view of the question and the completion of the an- 
swer.

- Transforming the categories into a theme.

The researchers discussed the categories and themes together to gain consensus. The analysis of the open questions resulted in a theme with underlying categories.

\subsection{Ethics Considerations}

The study was approved by the regional ethics committee in Lund (d. no: 2012/14) and the answers were treated with confidentiality.

\section{RESULTS}

\subsection{Quantitative Results}

A healthy sexual life was rated as important or very important by $57 \%$ of the participants. Sexual problems were expressed in the MDHAQ-S, question 5, by $30 \%$ of the participants. A negative effect of RA on their sexual health was described in the QSH, question 6, by $52 \%$ of the participants. Sexual well-being was described as not very good or worse by $52 \%$ of the participants. Level of sexual arousal was described as too low or non-existent by $65 \%$ of the participants, and $63 \%$ of the participants described that their sexual arousal had decreased after being diagnosed with RA. Sexual satisfaction after sexual activities was described to be weak or non-existent by $24 \%$ of the participants, and $43 \%$ of the participants described their sexual satisfaction as being lower after being diagnosed with RA.

\subsubsection{Correlation between Factors Included in the MDHAQ-S and the QSH}

The MDHAQ-S was tested for correlation with QSH for the physical dimension, the psychological dimension, pain, general well-being, fatigue, exercise level and BMI (Table 3).

There were significant correlations between the physical dimension of the MDHAQ-S and body image, decreased sexual arousal and decreased sexual health after onset of disease, as well as belief that a reduction of pain improved sexual health. The psychological dimension of the MDHAQ-S correlated significantly with body image, sexual well-being, worsened body image, decreased sexual arousal and decreased sexual satisfaction after onset of RA. A higher score on general pain showed a signifi-

Table 3. Correlation coefficients MDHAQ-S (significant correlations, $p \leq 0.05$ are marked in bold).

\begin{tabular}{|c|c|c|c|c|c|c|c|}
\hline & $\begin{array}{c}\text { MDHAQ-S } \\
\text { Physical } \\
\text { dimension }\end{array}$ & $\begin{array}{c}\text { MDHAQ-S } \\
\text { Physical } \\
\text { dimension }\end{array}$ & $\begin{array}{l}\text { MDHAQ-S } \\
2 \text { (pain) }\end{array}$ & $\begin{array}{c}\text { MDHAQ-S } \\
4 \text { (general } \\
\text { well-being) }\end{array}$ & $\begin{array}{c}\text { MDHAQ-S } \\
8 \text { (exercise level) }\end{array}$ & $\begin{array}{l}\text { MDHAQ-S } \\
9 \text { (fatigue) }\end{array}$ & BMI \\
\hline QSH4 (body image) & -0.355 & -0.317 & -0.231 & -0.243 & 0.090 & -0.093 & -0.123 \\
\hline QSH5 (changed body image) & -0.140 & -0.373 & -0.127 & -0.174 & 0.173 & -0.245 & 0.037 \\
\hline QSH6 (decreased sexual function) & -0.116 & -0.255 & -0.046 & -0.198 & 0.184 & -0.304 & 0.159 \\
\hline QSH8 (sexual well-being) & -0.226 & -0.397 & -0.382 & -0.381 & 0.156 & -0.141 & -0.180 \\
\hline QSH9 (sexual arousal) & -0.066 & -0.246 & -0.402 & -0.361 & 0.039 & -0.162 & -0.167 \\
\hline QSH10 (changed sexual arousal) & -0.284 & -0.288 & -0.399 & -0.469 & 0.218 & -0.216 & -0.016 \\
\hline QSH11 (sexual satisfaction) & -0.113 & -0.023 & -0.283 & -0.093 & 0.108 & 0.105 & -0.076 \\
\hline QSH12 (changed sexual satisfaction) & -0.303 & -0.305 & -0.538 & -0.455 & 0.184 & -0.155 & 0.060 \\
\hline QSH13 (satisfaction with relationship) & 0.254 & 0.062 & 0.238 & 0.086 & -0.104 & -0.160 & -0.072 \\
\hline QSH14 (effect on relationship) & 0.201 & 0.134 & -0.017 & 0.332 & 0.047 & 0.300 & -0.247 \\
\hline QSH15 (importance of sexuality) & -0.046 & 0.073 & -0.258 & -0.020 & 0.029 & 0.118 & -0.149 \\
\hline $\begin{array}{l}\text { QSH16 (connection between pain and } \\
\text { sexual health) }\end{array}$ & 0.337 & 0.108 & -0.074 & 0.067 & -0.285 & -0.085 & 0.016 \\
\hline $\begin{array}{l}\text { QSH17 (connection between stiffness } \\
\text { and sexual health) }\end{array}$ & 0.210 & 0.187 & 0.111 & 0.191 & -0.311 & 0.083 & 0.075 \\
\hline $\begin{array}{l}\text { QSH18 (connection between fatigue and } \\
\text { sexual health) }\end{array}$ & 0.041 & 0.148 & 0.106 & 0.160 & -0.184 & 0.085 & 0.058 \\
\hline $\begin{array}{l}\text { QSH19 (connection between physical } \\
\text { capacity and sexual health) }\end{array}$ & 0.169 & 0.129 & 0.142 & 0.158 & 0.121 & -0.052 & 0.365 \\
\hline
\end{tabular}


cant correlation with lower sexual well-being, lower sexual arousal, decreased sexual arousal since onset of RA and decreased sexual satisfaction after onset of RA. A poorer score on general well-being correlated significantly with lower sexual well-being, lower sexual arousal, decreased sexual arousal, decreased sexual satisfaction and worsened relationship with the partner since onset of RA. A high level of fatigue correlated significantly with RA affecting the possibilities to function sexually and with a worsened relationship with the partner. Level of exercise correlated with the belief that decreased morning stiffness improves sexual health. BMI correlated with believing that improved physical capacity improves sexual health.

\subsubsection{Predictors of Sexual Well-Being for Persons with RA}

The multiple regression analysis with sexual well-being as the criterion variable showed low Beta values for the items in the MDHAQ-S, indicating that the influence of the predictors on sexual well-being was low. There was however significance for the total score of the psychological dimension $(p=0.004, B$-value $=-0.345)$. The adjusted $\mathrm{R}$ square of 0.268 shows that our model accounts for $27 \%$ of the variance.

\subsubsection{Descriptive Statistics of Subgroups}

The group describing negative effects on their sexual health in the MDHAQ-S did not differ according to age or BMI. There were significant effects in several issues on the QSH for this group, such as: decreased ability to function sexually $(p=0.04)$, decreased sexual well-being $(p=0.03)$, decreased sexual arousal $(p=0.01)$, decreased sexual satisfaction after onset of RA $(p=0.02)$ and negative effect on intimate relationship of RA $(p=0.03)$.

Since several participants mentioned increased body weight due to RA in their open answers, and that this in turn affected their sexual health in a negative way, the group with a BMI representing overweight $(>25)$ was compared to the rest of the participants. The comparison showed a significant difference only for QSH, question 19: "I think there is a strong connection between improved physical capacity and improved sexual health" ( $p$ $=0.00)$.

There is a strong belief in $46 \%$ of the participants that increased physical capacity increases sexual health, and an additional $37 \%$ of the participants partly agree. In the studied group, $22 \%$ of the participants exercise more than three times per week and $52 \%$ exercise one to two times per week according to the MDHAQ-S, question 8: "How often do you exercise aerobically for at least one half hour?" There were no significant differences between the group exercising regularly and the group not exercising regularly.

\subsection{Qualititative Results}

\section{Description of the Participants' Reasoning Concerning Factors Affecting Their Sexual Health}

The open questions concerned experience of body image, sexual health, sexual relationship, sexual arousal, sexual satisfaction and eventual changes in those experiences due to RA. The open questions were analyzed according to the following key issues: "How has RA affected my experience of my body?" and "How has RA affected my sexual health?"

The categories included in "How has RA affected my experience of my body?" were physical changes (weight, appearance, physical function), changed experience of the body (changed body image, changed acceptance of the body, discontentment with the body) and effect of medication on the body. The body image was experienced to be less attractive after the diagnosis of RA. Increased body weight and feelings of being fat were mentioned by several participants as reasons for decreased sexual health and were experienced to be due to decreased physical ability owing to RA or to medical impacts. Loss of muscle and posture and developing a less attractive body shape were also considered to be effects of RA that had a negative effect on the participants' sexual health.

"Gained weight since the start of the disease and lost physical capacity and mobility".

"Have lost muscles, body shape and posture".

The participants also described negative feelings and aggression towards themselves and their body both in connection to sexual health and in general.

"Feels difficult not to be able to do as many things together as before, not only sexually".

Support for weight loss and increased exercise levels were considered an important strategy for improving sexual health.

"The last year's weight loss and exercise has given good effect".

Medication was described as both a way to improve and decrease sexual health. Some felt a direct improvement in being able to perform sexual activities, and others had experienced decreased sexual arousal due to medication.

"Before I had a diagnosis and medication I had a lot of pain and difficulties to move around in bed and everywhere. Now with medication, most things work".

"I have no sexual arousal since the start of medication with Humira".

The categories included in "How has RA affected my sexual health?" were changed physical functioning (pain, fatigue, changes in arousal, effects of age, decreased ability of intimacy) and effects on intimate relationships (acceptance within the relationship, worsening relation- 
ship, improved relationship).

"A body that aches and hurts with a single touch. Mucosal that feels like gravel. Tenderness and touch would be appreciated and needed, but sexual activity wouldn't work".

There were descriptions of partial or complete loss of sexual arousal and decreased ability to reach orgasm, both in connection with pain and fatigue and as single symptoms stemming from RA.

The effect on the intimate relationship depended largely on the couples' strategies for coping with the symptoms of RA and an understanding partner.

Among the strategies, acceptance of the disease and the related symptoms was important, both for the person with RA and the partner.

"Despite all negative things I have a very understanding husband and it helps a lot".

A strategy that was described by several participants was to exclude sexual activities from their life after the diagnosis, since sexual activities were considered difficult to perform. This strategy was described by several participants as unsatisfactory and also as troublesome in their relationship with their partner.

"Sex is a closed chapter of my life!"

"Would have needed help a lot earlier! Now it is unfortunately too late".

"He is disappointed in me because I can't perform intercourse due to pain and ache. He has difficulties to understand that my body hurts so much when being touched. Now after two years he has stopped nagging, but it has been a great physical strain on us both".

There were descriptions of wishes to regain a satisfactory love life with sexual activities or with new ways of sexual closeness and intimacy.

"Of course it would have been nice if it could work. Of course I miss it enormously".

The theme that emerged from the categories in the qualitative analysis was change. Change was important in how the symptoms of RA were experienced in connection with sexual health and how these changes were coped with.

\section{DISCUSSION}

The question on sexual health in the MDHAQ-S that shows decreased sexual health in this study group (30\%) is on a level with other studies concerning sexual health in patients with RA [4,5,21]. However, $52 \%$ of the participants describe their sexual well-being as being not very good/bad/very bad according to the QSH, indicating that the MDHAQ-S does not cover sexual health issues sufficiently. In comparison with the QSH, there are patients with decreased sexual arousal and decreased sexual satisfaction that are not detected by the question concerning sexual health in the MDHAQ-S. Sexual arousal seems to be more difficult to retain compared to sexual satisfaction since sexual satisfaction is rated higher in this group than the amount of persons describing a negative effect on sexual satisfaction due to RA. Decreased sexual arousal has been considered to be an important factor in persons with RA in other studies [29-31].

High scores in the psychological factors of the MDHAQ-S can indicate decreased sexual health after onset of RA and ought therefore to be considered important when communicating with patients about psychological effects of RA. Anxiety, feelings of depression and sleeping difficulties have a negative effect on sexual health in persons with rheumatological diseases [32,33]. Poorer sexual health can also increase anxiety and feelings of depression [29].

VAS scores on the MDHAQ-S for general pain, general well-being and fatigue should be considered when estimating whether a person is in need of discussing his or her sexual health since the scores can indicate decreased sexual health.

In our results, a high level of fatigue correlated with a higher impact of RA on the relationship with the partner as well as with the ability to function sexually. Research results considering the impact of fatigue on sexual health show mainly that fatigue has a negative effect on sexual health $[5,29,34,35]$, except in a study by Kobelt et al. that did not find significant support for fatigue influencing sexual health [36].

Pain has been shown in other studies to affect sexual health [6]. Our results showed that persons with higher VAS pain scores had lower sexual well-being and sexual arousal and that sexual arousal and sexual satisfaction had become worse since the onset of the disease. Those findings, together with earlier studies [33,35,37], give a clear indication that the issue of sexual health should be addressed when there is a high score for general pain on the VAS scale.

In a recent Swedish study, feeling lust was not a factor that promoted general health among persons with RA [38]. However, our study results showed that a lower general health score indicated lower sexual well-being, lower sexual arousal, a negative effect on the relationship with the partner and experienced decreased sexual arousal and sexual satisfaction since the onset of the disease. It is unknown whether the lower score of estimated general health indicates that poorer sexual health has given worse general health or vice versa. Good sexual health gives better general health, but low general health can also give low sexual health. Interest in sex and engaging in sexual activities decrease with poorer health [39].

The question of body weight is included in the MDHAQ-S, and weight gain can be an important issue in the experienced level of sexual health according to the 
open answers in this study. We believe this to be a factor that is important to acknowledge when considering factors that affect sexual health in a negative way among persons with RA. The quantitative results did not show significant differences for participants with a high BMI concerning the level of sexual health, but a person might feel overweight at a lower BMI depending on the body weight before the onset of RA. The feeling of being overweight can also be due to changes in muscular mass or body disposition, which does not show in the BMI. However, a low body esteem and weight concerns can decrease sexual satisfaction for women [40]. A negative body image has a negative effect on sexual health in women with RA [6,35,37]. A poorer body image correlated significantly with the physical and psychological factors of the MDHAQ-S, thus indicating that high scores on the psychological and the physical factors of the MDHAQ-S are reasons to address sexual health issues with the patient.

Physical fitness can affect sexual health positively, since improved fitness levels increase the frequency of sexual intimacy [41]. This is also shown for persons with RA [36]. It is interesting to note that this is perceived to be true by a majority of the informants, indicating that physical activity can be considered a self-help strategy to improve sexual health.

The theme change that developed from the analysis of the open questions can be compared with the results of a qualitative study by Helland et al. ([29] where the disease was considered to be an interruption in life that demanded new strategies for sexual issues and within the relationship. Our study results show both strategies that have led to a maintained sexual relationship and strategies that have led to an end of sexual activities. This change can be ongoing during the course of the disease with changes in medication, family life and disease activity, and we therefore believe that sexual health ought to be addressed regularly in rheumatologic health care, and especially when such changes are known.

We believe that a questionnaire indicating eventual sexual health difficulties can be useful in easing the conversation concerning sexual health without losing respect for the person's integrity. It is important to acknowledge that some patients with chronic diseases hesitate to bring up problems with sexual health with health care professionals since they do not believe that they can get any help from them [42]. Every health care professional must thus be aware of what types of sexual health problems their interventions can be of use for and in which cases they must refer the patient to another specialist.

A questionnaire can be of aid in finding key issues that imply decreased sexual health for persons with RA, but it is also essential to acknowledge other signs such as negative body image, a decrease in daily activities and changes in medication. When those factors are present, sexual health ought to be addressed, preferably by asking the patient if he/she would like information concerning how RA might affect sexual health or if he/she has any questions about this issue.

\section{Methodological Discussion}

Mixed methods research can be used to explore how the themes identified in the qualitative data collection compare with the statistical results in the quantitative analysis and, in our study, we found the qualitative categories to be in line with the quantitative results. Mixed methods can be used with a focus on the methods included, with employing the other research method to strengthen the results of the main method or by using both methods to complement each other. In this study, we used the latter alternative since we believe the two methods to be complementary and to make the results more applicable in clinical encounters between health care professionals and patients with RA.

The response rate of rate $67.5 \%$ is good for research concerning sexual health, since questionnaires concerning sexual health often have lower response rates $[31,43,44]$. The response rate is also good considering that older women are more reluctant to answer questionnaires about sexual issues, and this is the main group in this study $[5,31,45]$.

The QSH was used in this study owing to its validity and reliability in the Swedish context, as well as the inclusion of respondents that considered RA to be the cause of their sexual health difficulties. There are different questionnaires that are used to measure the impact of RA on sexual health. In the work of Palmer \& Miedany [46], there are four questions concerning intimate relationships and sexual function. Those questions had a narrow perspective of sexual health, however, and did not include whether the patient with RA saw RA as the cause of their sexual dysfunction, or how their sexual health was affected by their experienced sexual dysfunction. Another questionnaire, Qualisex [47], focuses on the experience of sexual health over last three months, which might be misleading if the respondents have felt their decreased sexual health since the onset of the disease.

The Stanford Health Assessment Questionnaire (HAQ) includes the physical dimension of the MDHAQ-S, measuring functional ability in daily activities, visual analogue pain scale and visual analogue general health scale [17], which is not sufficient to detect decreased sexual health. Another often used questionnaire is the Arthritis Impact Measurement Scale 2-Short Form (AIMS2-SF) [48], which covers physical, psychological, emotional and social status but lacks a description of body image issues, changes in medication, exercise habits and description of experienced symptoms of RA. To 
cover issues affecting sexual health, a health assessment questionnaire needs to have a broad scope that includes aspects of sexual health from a biopsychosocial perspective.

\section{CONCLUSION}

The MDHAQ-S covers sexual health issues, not only by using the question concerning sexual health but also by using other questions included in the questionnaire such as increased pain, fatigue, depression, anxiety, physical capacity, level of physical activity and body weight. To explore decreased sexual arousal, decreased sexual satisfaction and decreased sexual well-being, there is a need to make a deeper interview of persons with RA, either using a sexual health questionnaire or in a clinical interview. Improving communication about sexual health with respect for the person's integrity is essential, and further research into how this can be done is needed to improve sexual health in persons with RA.

\section{REFERENCES}

[1] World Health Organization (2006) Defining sexual health. Report of a technical consultation on sexual health, 28-31 January 2002, Geneva. Sexual health document series. Geneva, 35.

[2] Tasiemski, T., Angiaszwili-Biedna, N. and Wilski, M. (2009) Assessment of objective and subjective quality of life in people with rheumatoid arthritis - Preliminary study. Ortopedia Traumatologia Rehabilitacja, 11, 346-359.

[3] Sanderson, T., Morris, M., Calnan, M., Richards, P. and Hewlett, S. (2010) What outcomes from pharmacologic treatments are important to people with rheumatoid arthritis? Creating the basis of a patient core set. Arthritis Care \& Research, 62, 640-646. doi:10.1002/acr.20034

[4] Areskoug-Josefsson, K. and Oberg, U. (2009) A literature review of the sexual health of women with rheumatoid arthritis. Musculoskeletal Care, 7, 219-226. doi:10.1002/msc.152

[5] Helland, Y., Dagfinrud, H. and Kvien, T.K. (2008) Perceived influence of health status on sexual activity in RA patients: Associations with demographic and disease-related variables. Scandinavian Journal of Rheumatology, 37, 194-199.

[6] Yilmaz, H., Polat, H.A., Yilmaz, S.D., Erkin, G., Kucuksen, S., Salli, A. and Ugurlu, H. (2012) Evaluation of sexual dysfunction in women with rheumatoid arthritis: A controlled study. The Journal of Sexual Medicine, 10, 2664-2670.

[7] Palmer, D. and El Miedany, Y. (2011) Sexual dysfunction in rheumatoid arthritis: A hot but sensitive issue. British Journal of Nursing, 20, 1134-1137.

[8] Meana, M. and Jones, S. (2011) Developments and trends in sex therapy. Advances in Psychosomatic Medicine, 31, 57-71. doi: $10.1159 / 000328808$

[9] Bitzer, J., Platano, G., Tschudin, S. and Alder, J. (2007)
Sexual counseling for women in the context of physical diseases: A teaching model for physicians. The Journal of Sexual Medicine, 4, 29-37. doi:10.1111/j.1743-6109.2006.00395.x

[10] Couldrick, L., Gaynor, S. and Cross, V. (2010) Proposing a new sexual health model of practice for disability teams: The recognition model. International Journal of Therapy and Rehabilitation, 17, 290-298.

[11] Helland, Y., Garratt, A., Kjeken, I., Kvien, T.K. and Dagfinrud, H. (2013) Current practice and barriers to the management of sexual issues in rheumatology: Results of a survey of health professionals. Scandinavian Journal of Rheumatology, 42, 20-26. doi:10.3109/03009742.2012.709274

[12] Taylor, B. and Davis, S. (2006) Using the extended PLISSIT model to address sexual healthcare needs. Nursing Standard, 21, 35-40.

[13] El Miedany, Y., El Gaafary, M., El Aroussy, N., Youssef, S. and Ahmed, I. (2011) Sexual dysfunction in rheumatoid arthritis patients: Arthritis and beyond. Clinical Rheumatology, 4, 601-606.

[14] Pincus, T., Yazici, Y. and Bergman, M.J. (2009) Patient questionnaires in rheumatoid arthritis: Advantages and limitations as a quantitative, standardized scientific medical history. Rheumatic Disease Clinics of North America, 35, 735-743. doi:10.1016/j.rdc.2009.10.009

[15] Ekdahl, C., Eberhardt, K., Andersson, S.I. and Svensson, B. (1988) Assessing disability in patients with rheumatoid arthritis. Use of a Swedish version of the Stanford Health Assessment Questionnaire. Scandinavian Journal of Rheumatology, 17, 263-271. doi: $10.3109 / 03009748809098795$

[16] Fries, J.F., Spitz, P., Kraines, R.G. and Holman, H.R. (1980) Measurement of patient outcome in arthritis. Arthritis \& Rheumatism, 23, 137-145. doi:10.1002/art.1780230202

[17] Pincus, T. and Sokka, T. (2003) Quantitative measures for assessing rheumatoid arthritis in clinical trials and clinical care. Best Practice \& Research Clinical Rheumatology, 17, 753-781. doi:10.1016/S1521-6942(03)00077-9

[18] Pincus, T., Swearingen, C. and Wolfe, F. (1999) Toward a multidimensional Health Assessment Questionnaire (MDHAQ): Assessment of advanced activities of daily living and psychological status in the patient-friendly health assessment questionnaire format. Arthritis \& Rheumatism, 42, 2220-2230. doi:10.1002/1529-0131(199910)42:10<2220::AID-ANR2 6>3.0.CO;2-5

[19] Areskoug-Josefsson, K., Ekdahl, C., Jakobsson, U. and Gard, G. (2013) Swedish version of the multi dimensional health assessment questionnaire-Translation and psychometric evaluation. BMC Musculoskeletal Disorders 2013, 14:178 (4 June 2013).

[20] Pincus, T. (2007) A multidimensional health assessment questionnaire (MDHAQ) for all patients with rheumatic diseases to complete at all visits in standard clinical care. Bulletin of the NYU Hospital for Joint Diseases, 65, 150160.

[21] Josefsson, K.A. and Gard, G. (2012) Sexual health in 
patients with rheumatoid arthritis: Experiences, needs and communication with health care professionals. Musculoskeletal Care, 10, 76-89.

[22] Dures, E., Rumsey, N., Morris, M. and Gleeson, K. (2011) Mixed methods in health psychology: Theoretical and practical considerations of the third paradigm. Journal of Health Psychology, 16, 332-341. doi:10.1177/1359105310377537

[23] Shaw, J.A., Connelly, D.M. and Zecevic, A.A. (2010) Pragmatism in practice: Mixed methods research for physiotherapy. Physiotherapy Theory and Practice, 26, 510518. doi:10.3109/09593981003660222

[24] Wisdom, J.P., Cavaleri, M.A., Onwuegbuzie, A.J. and Green, C.A. (2012) Methodological reporting in qualitative, quantitative, and mixed methods health services research articles. Health Services Research, 47, 721-745. doi:10.1111/j.1475-6773.2011.01344.x

[25] Graneheim, U.H. and Lundman, B. (2004) Qualitative content analysis in nursing research: concepts, procedures and measures to achieve trustworthiness. Nurse Education Today, 24, 105-112. doi:10.1016/j.nedt.2003.10.001

[26] Areskoug Josefsson, K., Kammerlind, A.S. and SundLevander, M. (2012) Evidence-based practice in a multiprofessional context. International Journal of EvidenceBased Healthcare, 10, 117-125. doi:10.1111/j.1744-1609.2012.00263.x

[27] Kondracki, N.L., Wellman, N.S. and Amundson, D.R. (2002) Content analysis: Review of methods and their applications in nutrition education. Journal of Nutrition Education and Behavior, 34, 224-230. doi:10.1016/S1499-4046(06)60097-3

[28] Mayring, P. (2000) Qualitative content analysis qualitative social research. FQS, 1, Art.20.

[29] Helland, Y., Kjeken, I., Steen, E., Kvien, T.K., Hauge, M.I. and Dagfinrud, H. (2011) Rheumatic diseases and sexuality: Disease impact and self management strategies. Arthritis Care \& Research, 63, 743-750.

[30] Hill, J., Bird, H. and Thorpe, R. (2003) Effects of rheumatoid arthritis on sexual activity and relationships. Rheumatology (Oxford), 42, 280-286. doi:10.1093/rheumatology $/ \mathrm{keg} 079$

[31] van Berlo, W.T., van de Wiel, H.B., Taal, E., Rasker, J.J., Weijmar Schultz, W.C. and van Rijswijk, M.H. (2007) Sexual functioning of people with rheumatoid arthritis: A multicenter study. Clinical Rheumatology, 26, 30-38. doi:10.1007/s10067-006-0216-3

[32] Ozkorumak, E., Karkucak, M., Civil, F., Tiryaki, A. and Ozden, G. (2011) Sexual function in male patients with ankylosing spondylitis. International Journal of Impotence Research, 23, 262-267. doi:10.1038/ijir.2011.37

[33] Abdel-Nasser, A.M. and Ali, E.I. (2006) Determinants of sexual disability and dissatisfaction in female patients with rheumatoid arthritis. Clinical Rheumatology, 25, 822-830. doi:10.1007/s10067-005-0175-0

[34] Ostensen, M. (2004) New insights into sexual functioning and fertility in rheumatic diseases. Best Practice \& Research Clinical Rheumatology, 18, 219-232. doi:10.1016/i.berh.2004.01.002
[35] Rkain, H., Allali, F., Jroundi, I. and Hajjaj-Hassouni, N. (2006) Socioeconomic impact of rheumatoid arthritis in Morocco. Joint Bone Spine, 73, 278-283. doi:10.1016/j.jbspin.2005.03.021

[36] Kobelt, G., Woronoff, A.S., Bertholon, D.R., Texier-Richard, B., Gaigi, H., Perdriger, A., Maugars, Y., Combe, B. and Mimoun, S. (2010) Sexuality and relationship in patients with rheumatoid arthritis in France. Annals of the Rheumatic Diseases, 69, 358.

[37] Areskoug Josefsson, K. and Gard, G. (2010) Women's experiences of sexual health when living with Rheumatoid Arthritis-An explorative qualitative study. BMC Musculoskeletal Disorders, 11, 240. doi:10.1186/1471-2474-11-240

[38] Arvidsson, S., Arvidsson, B., Fridlund, B. and Bergman, S. (2011) Factors promoting health-related quality of life in people with rheumatic diseases: A 12 months longitudinal study. BMC Musculoskeletal Disorders, 12, 102. doi:10.1186/1471-2474-12-102

[39] Lindau, S.T. and Gavrilova, N. (2010) Sex, health, and years of sexually active life gained due to good health: Evidence from two US population based cross sectional surveys of ageing. BMJ, 340, c810. doi:10.1136/bmj.c810

[40] Pujols, Y., Meston, C.M. and Seal, B.N. (2009) The association between sexual satisfaction and body image in women. The Journal of Sexual Medicine, 7, 905-916. doi:10.1111/j.1743-6109.2009.01604.x

[41] Bortz, W.M., 2nd and Wallace, D.H. (1999) Physical fitness, aging, and sexuality. The Western Journal of Medicine, 170, 167-169.

[42] Kedde, H., van de Wiel, H., Schultz, W.W., Vanwesenbeeck, I. and Bender, J. (2012) Sexual health problems and associated help-seeking behavior of people with physical disabilities and chronic diseases. Journal of Sex \& Marital Therapy, 38, 63-78. doi:10.1080/0092623X.2011.569638

[43] Akkas, Y.N. and Kalyoncu, U. (2010) Factors affecting the sexual satisfaction of patients with rheumatoid arthritis and ankylosing spondylitis sexuality and disability. Sexuality and Disability, 28, 223-232.

[44] Laumann, E.O., Paik, A., Glasser, D.B., Kang, J.H., Wang, T., Levinson, B., Moreira, E.D., Jr., Nicolosi, A. and Gingell, C. (2006) A cross-national study of subjective sexual well-being among older women and men: Findings from the global study of sexual attitudes and behaviors. Archives of Sexual Behaviour, 35, 145-161. doi:10.1007/s10508-005-9005-3

[45] Fugl-Meyer, A.R. and Sjögren Fugl-Meyer, K. (1999) Sexual disabilities, problems and satisfaction in $18-74$ years old Swedes. Scandinavian Journal of Sexology, 2, 79-105.

[46] Palmer, D. and Miedany, Y.E. (2012) Sexual dysfunction in rheumatoid arthritis: A hot but sensitive issue. British Journal of Nursing, 20, 1134-1137.

[47] Gossec, L., Solano, C., Paternotte, S., Beauvais, C., Gaudin, P., von Krause, G., Sordet, C. and Perdriger, A. (2012) Elaboration and validation of a questionnaire (Qualisex) to assess the impact of rheumatoid arthritis on sexuality 
with patient involvement. Clinical and Experimental Rheumatology, 30, 505-513.

[48] Guillemin, F., Coste, J., Pouchot, J., Ghezail, M., Bregeon, C. and Sany, J. (1997) The AIMS2-SF: A short form of the arthritis impact measurement scales 2 . French quality of life in rheumatology group. Arthritis \& Rheumatism, 40, 1267-1274. 